\title{
High Voltage Grounding Design, Maintenance, Experience: A Case Study
}

\author{
${ }^{1}$ U. Mohan Rao, ${ }^{1}$ R.K. Jarial and ${ }^{2}$ D. Vijay Kumar \\ ${ }^{1}$ Department of Electrical and Electronics Engineering, \\ National Institute of Technology, 177005 Hamirpur, India \\ ${ }^{2}$ Department of Electrical, GITAM University, India
}

\begin{abstract}
Grounding and bonding protects and safeguards major assets and personnel in the aspect of electric shocks, fires and even electrocution. So, it is required that grounding should be effective in the strength of operation. Hence, a procure care is to be taken while designing and installing it. An effective grounding system seeks not only knowledge for its design but also efficient and experienced personnel for implementation of its design and keeping it up to survive for all the upcoming climatic conditions. Proper maintenance is even essential for expecting an effective service from the grounding system. In this study, a High Voltage Engineering Laboratory which was installed in the year, 1995 is considered and a detailed study has been carried out on its grounding system regarding its design and installation. The grounding mat of this laboratory has been monitored for a period of $>1$ year at regular intervals and the behaviour of the earthing mat for changing climatic conditions has been observed and found that this maintenance had meet the standards in terms of resistance. Keeping in mind about the new installations to be done in future and the installations which are already done, the maintenance methodology and the experience obtained in its maintenance are also presented in this study.
\end{abstract}

Key words: Earthing mat, electrode, grounding, high voltage engineering, installations, India

\section{INTRODUCTION}

The demand of electricity is growing ahead with advancements and automations of the existing technology. It is well known that location of electricity generating plant is normally quite far away from that of the consumers due to several technological reasons. The generated electricity is brought to the consumer installations for meeting their daily needs by means of overhead or underground transmission and distribution power system networks. This process of power evacuation prom generating power plants to load points involves the use of LV and HV electrical equipments handling various levels of power right from generating point to the equipments which are connected to the service terminals at the consumer end (Fig. 1). This process involves a huge capital investment along with human resource to install operate and maintain electrical power network. For a reliable and interrupt free operation of power system network several organisations at national and international level have suggested several guidelines with regard to protection and safety of the equipment and personnel. A careful implementation of the suggestive procedures embark upon installation of suitable LV and
HV grounding systems without which there may be a huge damage not only causing electrical injuries and shocks but will also result in electrocution to personnel handling the equipment. The basic aspect or the first and foremost step of protection is to maintain step and touch potential which can be assured by a perfect grounding system. At this stage one should be convinced that a perfect grounding system is essential for ensuring safety and reliability of smooth operation of power system network. If one should take proper care for the equipments in domestic usage and then one can imagine the care should be taken regarding grounding system at the point of transmission which involves high voltages. Here, exists a worthy word namely high voltage engineering which is a practice (generation, measuring and testing) done for handling the maintenance of equipments involved with high voltages. If this high voltage engineering is introduced to laboratory for students, it would result in the better advancement of R\&D. One such attempt is made in NIT-Hamirpur in 1995 which is funded by Centre of Excellence Grand of MHRD India. This high voltage laboratory being equipped with equipments handling with 100 's of $\mathrm{kV}$ is well grounded by installing a mat which is a network of 13 earthing

Corresponding Author: U. Mohan Rao, Department of Electrical and Electronics Engineering, National Institute of Technology, 177005 Hamirpur, India 
- Age of an earth electrode for which it is expected to serve in an efficient and reliable condition. If it is left as so left without proper condition monitoring it leads us to additional investments again to secure a proper grounding system

- Relation of soil resistivity with depth of earthing pit if it is a directly proportional relation then shallow electrodes are advised for inverse proportional relations deeper electrodes would be the solution (Singh et al., 2007)

- Condition maintenance of electrode such as scheduled watering using salt and charcoal

- Determination of alternatives in point of effectiveness if in case, the soil resistance is high

- Providing proper insurance against accidental losses through electrical shocks

- A typical grid usually is supplemented by a number of ground rods and may be further connected to auxiliary ground electrodes to lower its resistance with respect to remote earth (IEEE, 1987)

\section{CASE STUDY}

A High Voltage Engineering Laboratory installed in the year, 1995 at NIT-Hamirpur is considered and a detailed study of its importance, grounding design (grid and electrode) and experiences in its maintenance of electrode resistance are presented in this part of study. It has been noted that this lab contains $280 \mathrm{kV}$ impulse standard lightning, $280 \mathrm{kV}$ hvdc, $200 \mathrm{kV}$ hvac power frequency, $200 \mathrm{kV}$ power frequency string insulator, $100 \mathrm{kV}$ oil breakdown hvac, $100 \mathrm{kv}$ solid insulation breakdown voltage, $15 \mathrm{~cm}$ sphere air gap break down voltage and many more test sets which are clearly involving high levels of voltage are so are given with a proper grounding mat of 13 point electrodes.

Design of earth electrode and ground grid: Grounding system is a system which handles the protection of valuable/vital assets so utmost care should be taken in design point of view.

The basic aspects to be considered for a grounding system to be effective the following are to be satisfied:

- Electrode materials should be highly resistive to soil corrosion

- Electrodes must have enough current carrying capacity in order bypass the maximum available fault currents
- The condition of the soil such as moisture content, temperature of the soil, material content, type of soluble chemicals in the soil, concentration of soluble chemicals in the soil, contact resistance between the electrode and the soil, geometry of the current flow in the soil outward from the electrode to infinite earth (Zipse, 2001)

- Changes in the electrode resistances should not be permitted to vary appreciably from time to time and shall remain low enough to permit proper operation of the protective equipment and safety of the operators (Kuka, 1971)

In this High Voltage Engineering Laboratory during the process of installing grounding grid, a network of 13 earthing electrodes have been introduced by earth pits of dimension $(1 \times 1 \times 4) \mathrm{m}^{3}$ which and are spread within entire high voltage lab building as per the sectional layout shown in Fig. 2. Each earthing pipe is made up of GI material having diameter $50 \mathrm{~mm}$ and length $4.15 \mathrm{~m}$ with perforations each of diameter $9 \mathrm{~mm}$ around entire periphery of GI hollow pipe. At the bottom of GI pipe, a copper plate having dimensions $(300 \times 300 \times 6) \mathrm{mm}^{3}$ is

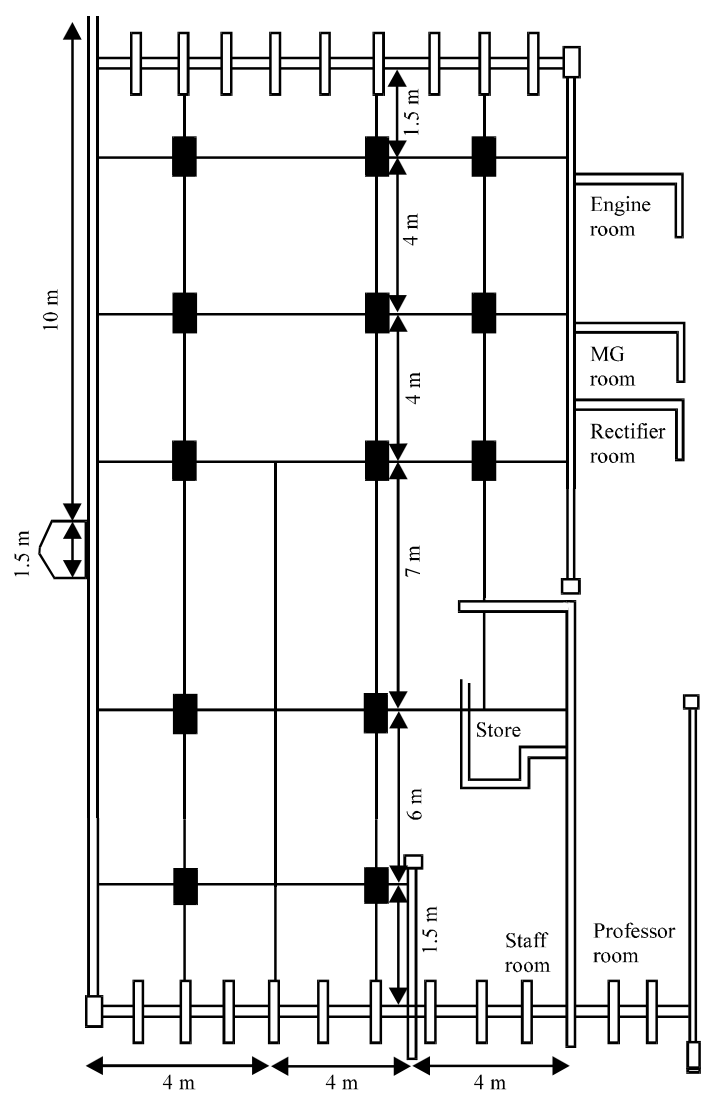

Fig. 2: Design/layout of grounding grid for the corresponding laboratory 


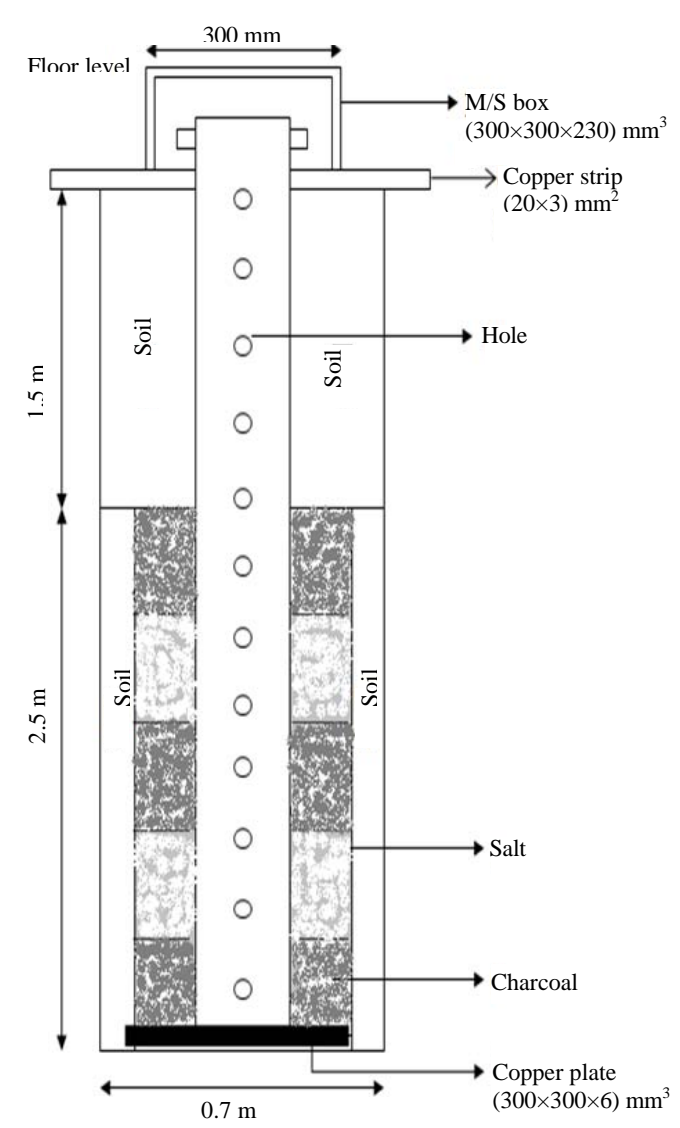

Fig. 3: Design of electrode dipped in the earth for earthing points

brazed. The top portion of GI is affixed with a mild steel box with dimensions $(300 \times 300 \times 230) \mathrm{mm}^{3}$ with a provision of opening lid to cover the top of earthing electrode. The base of the lid is also brazed to the GI pipe along with the copper strip of dimension $(20 \times 3) \mathrm{mm}^{2}$. After digging earthing pits, the GI earthing pipe is placed centrally with proper supports all around after putting soils at the bottom of earthing copper plate. After the charcoal layer of around $30 \mathrm{~cm}$ depth is poured to provide better earthing connectivity with the ground plane (Singh et al., 2007). Then soft soil of around $20 \mathrm{~cm}$ is spread around the charcoal layer extremities. Above the charcoal layer, a salt layer of $30 \mathrm{~cm}$ is spread around the axial pipe and the extremities is filled with soft soil and the process of putting alternate layers of charcoal and salt is repeated upto $2.5 \mathrm{~m}$ from the bottom. There after the soft soil is filled in the earthing pit around the GI pipe upto the floor level touching the lid at the top of earth rod as shown in Fig. 3.

A copper strip of $20 \times 3 \mathrm{~mm}^{2}$ is solidly brazed at the top end of GI pipe and is used for multiple network connection of the grounding mat. A complete layout of

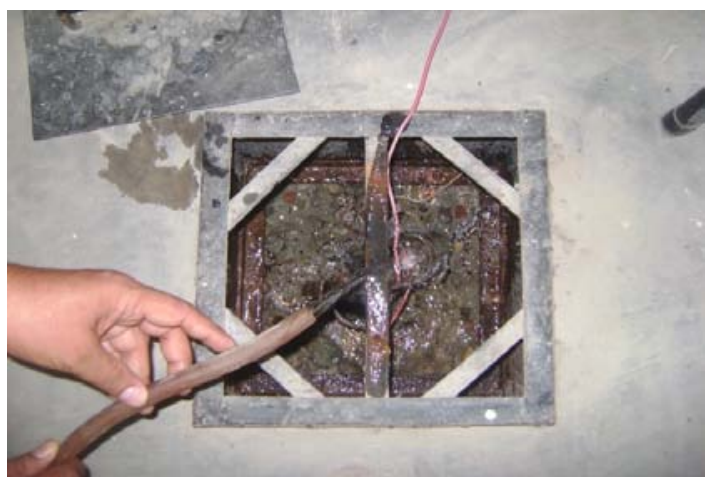

Fig. 4: Watering of electrode point in NIT-Hamirpur HVE laboratory

grounding mat consisting of 13 earth electrodes connected in the grounding grid form is shown in Fig. 3. So one can now imagine the entire grounding system of the lab in a 3 axis plane by imagining (Fig. 3) 13 times on all 13 black darken rectangles shown in Fig. 2.

Maintenance of earth grid: For knowing the functionality strength status of any ground grid, it should be ensured that its resistance is always low and mostly must never exceed than $1 \Omega$. Proper maintenance is to be taken in order to maintain its resistance in desirable limits. If the resistance of the grounding grid is more, it may not function properly and may lead to hazards which will be a factor of incurring loss to valuable assets and personnel. For the maintenance of the existing laboratory's ground mat watering of the mat has been done frequently by pouring water directly into the mild steel box situated exactly at the top of earthing electrode as shown in Fig. 4.

This mat resistance has been monitored continuously for a period of $>1$ year from $6 / 1 / 2009$ to $25 / 5 / 2010$ by using three point method and observed the values of the earth resistance and found that even though there are variations in the values but it is being operating in safe limits as its resistance had never crossed $1 \Omega$. Various values of earth resistance obtained at the particular test dates are plotted on a two axis space with $\mathrm{X}$-axis being test dates and $\mathrm{Y}$-axis as earth resistance values and the corresponding curve as shown in Fig. 5. On observing the plot it has been found that during April and May months of the year 2009, the measured mat resistance is $0.91 \Omega$ and this value is exactly repeated again in the same months of next year, i.e., 2010 which are the maximum values of the resistances of the mat ever found in the study and it is noted that during these months the atmospheric temperature is around $28-30^{\circ} \mathrm{C}$ during day time and $23-26^{\circ} \mathrm{C}$ during night time. In the month of January and February of these 2 consecutive years the 




Fig. 5: Resistance of mat against the test dates showing climatic variations

mat resistance values are $0.81,0.81$ and $0.8,0.83 \Omega$, respectively and the average temperature during these months are $5-10^{\circ} \mathrm{C}$ during day time and it freezes to $0^{\circ} \mathrm{C}$ and even negative values as the night progresses. It is also observed that in June-August months, there is a gradual decrease in the resistance this is because of the rainy season (He et al., 2003). Hence, the soil will be wet during rainy season, the resistance of the mat had decreased gradually.

\section{CONCLUSION}

In this study, a practical approach to a high voltage grounding mat in the aspect of design, maintenance and monitoring experience are presented which can be used for new installations, maintenance in order to meet the existing standards in terms of the mat health. Ground mats behavior for various temperatures and the details are given. Procedures for maintenance are also presented in detail. It is hereby requested for the researches to develop new methodologies and standards to improve the quality of protection to the equipment and personnel.

\section{REFERENCES}

ANSI/IEEE Std., 2000. IEEE 80-2000: Guide for safety in AC substation grounding. Proceedings of the IEEE Power Engineering Society Substation Committee, July 14, IEEE Power and Energy Society, pp: 1-192.

Gupta, B.R., 2008. Electrical Power System. In: Power System Analysis and Design. Gupta, B.R. (Ed.). S. Chand and Company Limited, New Delhi, ISBN: 9788121922388, pp: 554-570.

He, J., R. Zeng, Y. Gao, Y. Tu, W. Sun, J. Zou and Z. Guan, 2003. Seasonal influences on safety of substation grounding system. IEEE. Trans. Power Delivery, 18: 788-795.

IEEE, 1987. IEEE Guide for Generating Station Grounding. S. Chand Company Limited, USA.

Kuka, K.S., 1971. Electric shocks and safety earthing. J. Inst. Eng. Electr. Engerg Div., 51: 140-154.

Singh, J., P. Verrma, R.K. Jarial and Y.R. Sood, 2007. Earthing of high voltage laboratory. Int. J. Electr. Power Eng., 1: 353-358.

Zipse, D.W., 2001. Earthing-grounding methods: A primer. Proceedings of the IEEE Industry Applications Society 48th Annual Petroleum and Chemical Industry Conference, September 24-26, 2001, Toronto, Ont., Canada, pp: 11-30. 